\title{
The Healing Power of Dialogos Dialogues: Transformative Learning through Dialogical Philosophizing
}

\author{
Guro Hansen Helskog \\ Department of Education and School Development, Buskerud and Vestfold University College, \\ Drammen, Norway \\ Email: guro.helskog@hbv.no
}

Received August 2014

\begin{abstract}
To what extent might Dialogos philosophical dialogues conducted over time have therapeutical or healing effect? This is the question explored in this paper. Drawing on the model of Mezirow, transformative learning theory is applied to excerpts of qualitative empirical material from the Gandhi Project, an action research project aimed at trying out the Dialogos approach to practical philosophy in intercultural and interfaith educational contexts. Students claimed to have gained selfknowledge and knowledge of others, and that they had enhanced their social courage as well as their ability to cope with problems, personal or other, both in school and in general life. In general, they reported that they had become more mature through the project. The conclusion is that the approach is promising when transformative learning and psychological healing is made an aim of education.
\end{abstract}

\section{Keywords}

Psychological Healing, Transformative Learning, Philosophical Dialogue, Intercultural Education, Interreligious Dialogue

\section{Introduction}

Transformative learning theory is a theory of deep learning that goes beyond mere content knowledge acquisition and learning of skills. It is claimed to be a process for adults to learn to think for themselves. It can involve personal transformation of what our personalities may predispose us towards, or what our conceptions makes us believe about other individuals or groups of people [1] [2] [9]. This paper applies transformative learning theory to empirical material drawn from the Gandhi Project—an intercultural and interreligious philosophical dialogue project consisting of ten philosophical dialogues based in the Dialogos approach to dialogical philosophizing. Dialogos is a series of six books consisting text material, questions, quotations, illustrations and exercises intended as points of departure in philosophical dialogues in secondary, upper secondary and adult education [4] [5]. Dialogical philosophizing implies joint truth searching through collaborative wonder, interpretation, analysis, exploration and conceptualization in the pursuit of answering fundamental questions with philosophical content. The 
overarching research question can be presented as follows: To what extent might Dialogos philosophical dialogues conducted over time have therapeutical or healing effect?

The paper is structured as follows: In Section 2 Mezirow's theory of transformative learning is outlined. Section 3 describes research design, material and methods in the Gandhi project. Section 4 outlines results, while Section 5 provides an analysis. Finally, the conclusion is drawn in Section 6.

\section{Transformative Learning Theory}

The concept transformative learning was developed by Jack Mezirow in 1978 as a theory of adult learning [6] [7] [9]. His theory aimed at explaining how adults change the way they interpret their world. Transformative learning is defined as the process of effecting change in a frame of reference [7]. A frame of reference is primarily the result of the influences of primary care givers and of cultural assimilation, and it is defined as encompassing cognitive, conative and emotional components, composed by two different dimensions: Habits of mind and a point of view. Mezirow defines habits of mind as broad, abstract, orienting and habitual ways of thinking, feeling and acting influenced by assumptions that constitutes a set of codes that may be cultural, educational, social, political, economic or psychological. He introduces ethnocentrism as an example of a habit of mind. Ethnocentrism is the predisposition to regard others outside one's group as inferior, creating a point of view that constitutes the complex of beliefs, feelings, attitudes and judgments we have regarding specific individuals or groups. A habit of mind is more durable than points of views. Points of views are constantly changing as we reflect on either the content or process by which we solve problems and modify assumptions. Mezirow states that we transform our frames of reference through the critical reflection on the assumptions upon which our interpretations, beliefs and habits or mind or points of view are based. Self-reflection can lead to significant personal transformation. Mezirow [7] differentiates four processes of learning based in transformative learning theory, exemplifying by ethnocentrism:

1. We elaborate the existing frame of reference-seeking further evidence to support an initial bias or conviction about another group of people

2. We learn new frames of references by for instance encountering new groups and creating new negative meaning schemes for them by focusing on their perceived shortcomings

3. We transform our point of view by for instance having an experience in another culture that results in our critically reflecting on our misconceptions of this particular group. The result may be a change in point of view toward the group involved. As a result, we may become more tolerant or more accepting of members of that group. If it happens over and over again with a number of different groups, it can lead to a transformation of our governing habit of mind.

4. We transform our habit of mind by for instance becoming aware and critically reflective of our generalized bias in the way we view groups other than our own. Such epochal transformations are less common and more difficult. Moreover: We do not make transformative changes in the way we learn as long as what we learn fits in our existing frames of reference.

\section{Research Design, Material and Method}

This paper applies the conceptual framework of Mezirow [7] to material from the Gandhi Project. The project was designed as a qualitative action research project consisting of ten philosophical dialogues in a group of strategically recruited students with Muslim (shia and sunni) and Christian, atheist and agnostic worldviews. The action research design [6] made it possible to adjust the project as it developed, as in the action research model of [1]: diagnosis, planning, action (dialogue) and evaluation, then new diagnosis, planning, action and evaluation, repeated ten times. Each dialogue lasted approximately 1.5 hours. Material consisted of pre-test texts, student meta-reflection notes, observation and reflection notes, post-test texts and post-test, video recording of dialogue session nine, and a semi-structured interview five months after the project was over. Data material was analyzed and categorized under phases drawn from transformative learning theory. In this paper I have chosen to focus only on the starting point situation and the situation after the project was over, due to space limitations.

The pre-test assignment made visible aspects of the existent frames of references which the students brought into the project dialogue process. The starting point situation in the Gandhi project can be characterized with the notion ignorance and distance, and only to some extent suspicion and fear towards fellow students with a more or less obviously different cultural or religious background than one self. This was part of what Mezirow [7] 
calls the existing frame of reference of the students. Suspicion and fear of strangers might be understood as forms of xenophobia, even though xenophobia often is regarded as bordering on racism, which might be, but is not necessarily included in the expression "fear of strangers". Especially one of the students had admitted attitudes that bordered on xenophobia and racism in her pre-test text. She wrote that "I am very critical towards people who have another background than me. This is not something I like about myself, but it comes naturally to me". She added that "I easily dislike other people, and do not easily like them (especially people with another skin color than myself). This is something that I would like to change, because I do not want to be 'racist'. But if I like them, I easily like others of the same 'race' as well.” As a contrast, one student with a minority background wrote that now that she lived in Norway she sees, speaks to and keeps "in touch with people from different countries, backgrounds and religions". These were the themes and/or questions explored in each philosophical dialogue, all drawn from (4):

1. Philosophical questions: Is it right to help people die? And: What does it mean to listen? (Dialogos, ex. 4 and 5, pp. 18-20).

2. What makes us different individuals? [3], exercise 47, pp. 112-113.

3. Human rights [3], exercise 17, pp. 42-43.

4. To control one's mind—a dialogue with Buddha [3], exercise 80, pp. 196-197.

5. The order of the universe-a dialogue with Muhammed [3], exercise 81, pp. 198-199.

6. In the beginning was wisdom—a dialogue with Jesus [3], exercise 82, pp. 200-201.

7. Equality [3], exercise 16, pp. 40-41.

8. The observations of the alien from outer space: Good and bad [3], exercise 9, p. 30.

9. What does it mean to be happy? [3], exercise 43, pp. 100-101.

10. What is peace? [3], exercise 85, pp. 212-213.

\section{Results}

The Gandhi Project lasted for approximately three months. The participant who had described herself as relatively xenophobic and racist in the beginning of the project was in the post test describing a personal transformation that has come about due to the dialogue project:

"I used to be critical against living together with people with a different background and way of living/view of life. This was not something I wanted, and therefore I am very happy to have been part of the Gandhi project, because this view changed a lot, and I now feel I respect and understand other cultures in a better way. So living with these people I now see as useful. We can learn a lot from other cultures, and they inspire us to think new and differently."

The Muslim participants responded, looking directly at her, one of them saying: "I never thought I would get in touch with someone like you (either). You were so closed and you had such a dark, black style. You have changed a lot, I think! [...] When you started speaking to me and showed that you were nice, my views on you changed. I saw you in a different way". Others joined in: "We have such stupid conceptions that because people look such and such, they are so and so, and judge by that. Now I do not do that anymore" and: "I have met myself in the doorway, and seen that it is stupid to judge before you know people". The expressions from the Christian participants are representative for the attitudes that had developed within the individuals and collectively in the group-between the individuals:

"I think differently after the Gandhi project. By respecting each other's thoughts, view of life and so on, and the fact that it is possible to find something good in it/in the other and let go of some of one's own leads towards peace and harmony_Philosophical dialogues are possible if there are disagreement and mess, then I think one often will see that the problem disappears because one "takes a look into oneself".

Students also claimed they had become socially more confident and generally more mature through the project, like this young Muslim woman: "I have learned a lot of new things about religions, about how people feel and think, and I more easily understand others. After this, it has been easier to listen and respond to different opinions. One grows a lot more, and become a positive person". She states that dialogical philosophizing "makes you become much wiser and lets you grow as a human being". Moreover, it "makes you understand and respect other cultures and religions better, and it helps you in other school subjects, because of the learning outcome of the philosophical dialogues". She also states that "your communication with other human beings is enhanced", claiming that it "can actually create peace through understanding". Finally, she argues that philosophical Dialogos dialogues are "interesting and makes it easier and more fun to learn", adding that dialogues "might make 
you change your opinions”.

In an interview five months after the Gandhi Project was finished, a student with a background as a single minor refugee, told that "When we started the project, it was as if I was trapped inside of a ring. It was narrow inside of me. When I encountered a problem, whether it was at school or in life in general, I stopped. I did not go further. I gave up. Then during the project it was as if something exploded inside of me, like an atomic bomb". He formed the shape of a bomb with his arms, illustrating his experience. "It was as if I was looking into an endless horizon". Taking down his arms, he continued: "Now, when I encounter a problem, whether in general life or in school work, I do not stop anymore. I know there is a way, and I continue”. A Muslim student is expressing that the outcome of the Gandhi project was "increased respect and understanding, less prejudice, more openness towards other people, dare to ask more (...). I could feel that this emerged by the fact that I have tried to keep in touch with more people, dare to speak to others”.

\section{Discussion}

Mezirow [6] [7] defines transformative learning as the process of effecting change in a frame of reference through changes in points of view and habits of mind. Data from the Gandhi Project indicate that the students had learned new frames of references by encountering students with other backgrounds than their own, and to some extent also altering these frames of references. They are re-specting, i.e. looking again at-some of their former views, critically reflecting on their misconceptions of each other, implying transformation of points of views. They became more tolerant or more accepting of the others. Mezirow states that if this happens over and over again with a number of different groups, it can lead to a transformation of our governing habit of mind. The Gandhi Project invited the students to philosophize together for three months, preparing the ground for such a transformation. They became aware and critically reflective of their generalized bias in the way they viewed groups other than their own. Moreover, students had become free of forces that had limited their options. The Burmese student had earlier given up when encountering a problem, he said. Now, he knows there is always a way. This transformation had not only affected his life at school, but also his general life, which to some extent was renewed, resulting in a completely new way of relating in life, due to the philosophical dialogue project. He described it as a healing and therapeutic process, which had also been touched upon by other students in their written post-test assignments and project evaluations after many of the dialogues as well: The dialogues had functioned as therapy to them. Many students claimed they had become socially more confident and courageous due to the project, implying that they to a greater extent dared to take contact and sustain contact with more people. This implied becoming free of inner (or outer) structures that hindered the students in living a healthy social life. The process involved emancipation from the unquestioned acceptance of what students had previously come to learn through life experiences. They were encouraged to question and reflect upon existing perspectives, explore alternatives and create new perspectives which were reintegrated and grounded with their previous perspectives and experiences.

\section{Conclusion and Final Remark}

The overarching research question of this paper was To what extent might Dialogos philosophical dialogues conducted over time have therapeutical or healing effect? Based on the analysis above, it is possible to conclude that philosophical dialogues conducted over time are at least promising when transformative learning is made the purpose of educational practice. The process enhanced students' general quality of life, indicating that philosophical dialogues can be psychologically healing and promote better mental health across cultural differences. The conclusion is utterly supported and justified elsewhere, for instance in [8] and [3]. The latter paper is an account of an action research project aimed at bringing about reconciliation in a severe conflict in upper secondary multicultural and multi-faith education a few months after the Gandhi project was completed [5]. The starting point situation was students suffering somatic and psychological problems due to the conflict. Some were scared of going to school, and some wanted to quit. Also this project consisted of ten philosophical Dialogos dialogues, and the process resulted in reconciliation and a better learning environment in the class, indicating that Dialogos dialogues might have therapeutic and health promoting effect.

\section{References}

[1] Coghlan, D. and Brannick, T. (2001) Doing Action Research in Your Own Organization. Sage, London. 
[2] Cranton, P. (2006) Understanding and Promoting Transformative Learning. Jossey-Bass, San Francisco.

[3] Helskog, G.H. and Ribe, A. (2009) Dialogos_-Veiledning for Lærere og Samtaleledere. Fagbokforlaget, Bergen.

[4] Helskog, G.H. and Ribe, A. (2008) Dialogos_Praktisk Filosofi i Skolen. Fagbokforlaget, Bergen.

[5] Helskog, G.H. (2014) Moving out of Conflict into Reconciliation. Bildung through Philosophical Dialogue in Intercultural and Interreligious Education. An Action Research Project in Upper Secondary Education. Educational Action Research, Online. http://dx.doi.org./10.1080/09650792.2014.882262

[6] Mezirow, J. (1978) Perspective Transformation. Adult Education Quarterly, 28, 100-110. http://dx.doi.org/10.1177/074171367802800202

[7] Mezirow, J. (1997) Transformative Learning: Theory to Practice. New Directions for Adult and Continuing Education, 74, 5-12. http://dx.doi.org/10.1002/ace.7401

[8] Stokke, C. and Helskog, G.H. (In Print) Promoting Dialogical Democracy. Dialogos Dialogues in Inter-Cultural and Interfaith Education. Studies in Interreligious Dialogue.

[9] Taylor, E.W. (2008) Transformative Learning Theory. New Directions for Adult and Continuing Education, 2008, 5-15. http://dx.doi.org/10.1002/ace.301 